\title{
La eco-geo-política del agua: una propuesta desde los territorios en las luchas por la recuperación del agua en la provincia de Petorca (Zona central de Chile)
}

Recibido: 20 de agosto 2017

Revisado: 5 de octubre 2017

Aprobado: 2 de noviembre 2017

Paola Bolados García Chilena. Doctora en Antropología. Académica de la Escuela de Trabajo Social de la

Universidad de Valparaíso.

Convenio de Desempeño de Humanidades, Artes y Ciencias Sociales. Chile. Correo electrónico: paola.bolados@uv.cl

Fabiola Henríquez Olguín Chilena. Licenciada en Historia.

Chile.

Correo electónico: fabiolahenriquez0@gmail.com

Cristian Ceruti Mahn Chileno. Magister en Desarrollo Regional, Estudiante del Doctorado en Estudios Interdisciplinario sobre Pensamiento, Cultura y Sociedad de la Universidad de Valparaíso, Chile. Correo electónico: cristian.ceruti@postgrado.uv.cl

Alejandra Sánchez Cuevas

Chilena. Magister en Psicología. Estudiante del Doctorado en Estudios Interdisciplinario sobre Pensamiento, Cultura y Sociedad de la Universidad de Valparaíso, Chile. Correo electónico: deiuv2016@gmail.com
Resumen: Desde los aportes de la ecología política latinoamericana y de la geografía crítica, relevamos las eco-geo-políticas del agua desde los territorios que surgen de las prácticas y los discursos del Movimiento por la Defensa del Agua, la Tierra y el Medio Ambiente y sus luchas por la recuperación del agua. A partir de un trabajo etnográfico basado en entrevistas a pequeños agricultores y el análisis de los derechos de aguas entregados por el Estado, mostramos el conflicto por el agua de la provincia de Petorca como un conflicto eminentemente por la tierra, el cual se radicalizó a partir del Código de Aguas impuesto por la dictadura militar en 1981 y se profundizó con la expansión de las fronteras extractivistas agroexportadoras desde el retorno a la democracia en los años 90.

Palabras clave: extractivismo; agro-exportación; MODATIMA; política de aguas en Chile

An Eco-Geo-Politic of Water: A proposal from the Territories in the Struggles for the Reclamation df Water in Petorca Province

(Central Zone of Chile)

Abstract: Building upon the contribution of the Latin-American Political Ecology and Critical Geography, we highlight the eco-geo-politics of water from the territories that rise from the practices and discourses of the Movement for the Defense of Water, Land and Environment in the Petorca Province, central zone and its struggle for the reclamation of water. From an ethnographic approach based on interviews with small farmers and an analysis of the water rights granted by the state, we present the struggle for water in Petorca as a historical conflict for the land, which became more radical since the imposition of the water code by the military dictarorship in 1981, and compounded with the expansion of the agro-exportation extractivist frontiers since democracy returned in 1990.

Key words: extractivism; agro-exportation; MODATIMA; water policy in Chile 


\section{Introducción}

El surgimiento del Movimiento por la Defensa del Agua, la Tierra y el Medio Ambiente (MODATIMA) en la provincia de Petorca representa uno de los casos emblemáticos en la lucha por la recuperación del agua en Chile. Este conflicto irrumpió a nivel de los medios de comunicación en el 2012, a partir de una denuncia realizada por el dirigente Rodrigo Mundaca, quien, por primera vez, habló públicamente sobre robo de agua y dio los nombres de quienes la usurpaban por medio de drenes ilegales construidos en torno a los ríos Petorca y La Ligua (ambos con restricciones y protecciones de extracción desde la década de los años 90). Emblemático fue dicho evento porque hizo público un hecho que se sabía desde fines del siglo pasado, pero que se volvió aún más evidente en la década del 2000, una vez que se otorgaron derechos de aguas en medio de múltiples discursos sobre la sequía y la escasez, promovidos por agentes privados y estatales. A su vez, mostró la fuerza y vigencia de la legislación impuesta en la dictadura, en particular del Código de Aguas de 1981, y las insuficiencias institucionales y legales para hacer efectivas las protecciones otorgadas por la entidad encargada de la administración del agua en Chile (la Dirección General de Aguas -DGA-). El caso reveló también las consecuencias criminalizantes por denunciar estas ilegalidades, las cuales significaron una condena al dirigente denunciante y una criminalización de MODATIMA. No obstante, la incansable lucha de esta organización reinstaló la discusión parlamentaria sobre la reforma al Código de Aguas, y logró que se recuperaran derechos provisionales entregados en la década del 2000 a titulares que habían sido denunciados por MODATIMA, y cuyo proceder fue reconocido luego, tardíamente, por la propia DGA.

El caso de MODATIMA en Chile, no solo abre el cuestionamiento respecto de la privatización de las aguas y la tragedia que significó para Petorca y muchos otros territorios perder a sus pequeños agricultores en pos de la política agroexportadora impulsada en los años 80 y profundizada con el retorno a la democracia en la década de los años 90. El agronegocio, el monocultivo, los agrotóxicos, el sobreotorgamiento de derechos de aguas y su sobreexplotación fueron temas que este movimiento instaló en la agenda de la política pública, marcando una inflexión en la crítica social y política que encauzaron las organizaciones y comunidades afectadas por la privatización de las aguas en Chile anteriormente. Preguntas como: ¿quién tiene las aguas?, ¿cuáles son los usos privilegiados?, así como ¿por qué el Senado de la Nación tardó casi dos décadas para avanzar en la reforma al Código de Aguas? se instalaron en la ciudadanía, producto del trabajo de MODATIMA y de agrupaciones y redes que comenzaron a cuestionar el modelo exportador chileno y sus consecuencias para los territorios y sus comunidades. 
Hasta entonces, Chile representaba un ejemplo exitoso del modelo neoliberal privatizador, que lograba compatibilizar crecimiento económico con justicia social, pero no con justicia socioambiental. Durante el retorno a la democracia y pese a las legislaciones democratizadoras y proteccionistas del medio ambiente como la Ley Indígena y la Ley de Medio Ambiente en 1993 y 1994, respectivamente, se observó que la transición política estaba alineada con la economía global, y que en particular no se opondría a la expansión minera, salmonera, agroexportadora y forestal que durante esas décadas evidenciaron un crecimiento exponencial. Chile fue uno de los primeros países en crear un mercado de aguas, y uno de los más eficaces en instalar discursos y prácticas tendientes a legitimar los usos productivos y energéticos que el Código de Aguas estableció, ${ }^{1}$. Paralelamente, los cambios legislativos desplegados en el marco de la violencia de la dictadura fueron reemplazados por discursos tecno-burocráticos que elitizaron el conocimiento ambiental y marginaron la entrada de perspectivas críticas como las del pensamiento decolonial, la ecología política y la geografía crítica. Solo los expertos fueron autorizados para hablar del medio ambiente o las aguas, así como los únicos encargados de administrar y gestionar los debates en torno a sus usos. En su mayoría eran biólogos, ecólogos e ingenieros que desarrollaron una perspectiva tecnificada de la naturaleza a partir de los lineamientos de la Ley de Medio Ambiente. Hasta entonces la propia literatura sobre extractivismo era analizada exclusivamente en el campo de las organizaciones sociales, ambientales y no gubernamentales (ONGs); y marginada en gran parte en la academia y en la literatura especializa. ${ }^{2}$

El caso de Chile sería relevante entonces no solo por ser el primero en implementar un modelo neoliberal de estas características y con él, uno de los códigos de aguas y mercado de aguas más liberales del mundo. Su importancia radicaría también con respecto a que la institucionalidad del agua se instalaría en Chile durante la dictadura, la cual junto al Código de Aguas y minero de los años 1981 y 1982, crearían organismos como la Comisión Nacional de Riego (CNR) -destinado a apoyar a los grandes empresarios-, y también darían vida a las Asociaciones de Agua Potable Rural (APR), por las cuales el Estado desligaría su obligación en la distribución del agua potable rural. En aquel momento, las APR aparecerán como organizaciones autónomas; pero tendrán que lidiar progresivamente con las desigualdades en la distribución del agua. En particular el caso de Petorca, nos mostrará la complejidad en torno a los conflictos por el agua, en tanto construye un círculo socio-ambientalmente vicioso pero lucrativamente virtuoso, que abarca inicialmente la privatización de las aguas superficiales y subterráneas, luego de las aguas sanitarias (que terminarán por ser privatizadas en los gobiernos socialistas de Ricardo Lagos -2000-2006-); se cerrará finalmente el círculo con la industria de la escasez y la sequía, y las dudas de la calidad del agua potable, las cuales obligaron a la compra de agua embotellada en las localidades que fueron, antaño, poseedoras de agua suficiente y limpia. La crisis y los conflictos por el agua en Petorca nos mostrarán, entonces, la forma de operar del modelo de aguas por su neoliberalización y su monopolización en manos de empresas agroexportadoras, las cuales contarán con el apoyo legal y finan-
1. Esto lo realizó por medio de la separación de las aguas consuntivas y no consuntivas como dos categorías. La primera con finalidad de consumo y la segunda con finalidad de utilización energética.

2. Los primeros trabajos que abordaron los conflictos por el agua desde la ecología política fueron los de Jessica Budds en la década de los 2000. En tanto los trabajos coetáneos de Carl Bauer centraron su análisis en el mercado de aguas, fundamentalmente como un problema de gestión y administración. 
3. Este artículo es resultado de un proyecto de investigación desarrollado durante los años 2014 al 2017 en la región de Valparaíso. El trabajo etnográfico recogió 15 entrevistas a agricultores de la Provincia de Petorca, en especial de las comunas más afectadas por la usurpación de aguas en Cabildo, La Ligua y Petorca. Las entrevistas fueron a miembros de MODATIMA, de las cuales 5 fueron a mujeres $y$ 10 a hombres de diversas edades. Las entrevistas fueron de carácter etnográficas, es decir no directivas y se realizaron en el territorio durante el transcurso del año 2015. Las fuentes secundarias se centraron en los informes de los organismos del Instituto Nacional de Derechos Humanos, del observatorio de la Universidad Diego Portales e informes de la Dirección General de Aguas. Se incorpora información de las inversiones entregadas por la Comisión Nacional de Riego y la CORFO durante el período estudiado. ciero para consagrar un modelo de despojo territorial que profundizará aún más la pobreza y la marginación de las comunidades en su acceso a bienes públicos y sociales como el agua y la tierra.

El acercamiento al caso de Petorca y con él, al análisis del caso de Chile como ejemplo de la privatización de las aguas, lo haremos retomando los análisis críticos de la decolonialidad, la ecología política latinoamericana y la geografía crítica, ámbitos que nos permitirán mostrar las dimensiones políticas de los conflictos por el agua y la convergencia de factores globales, nacionales, regionales y locales que median las políticas globales actuales y sus configuraciones posdictatoriales. Desde estas aproximaciones teóricas, analizaremos la información cualitativa basada en las entrevistas a agricultores de Petorca y miembros de MODATIMA y la información cuantitativa disponible; se mostrará en particular cómo se levanta la industria de la sequía y la escasez para ejecutar una privatización radical del agua en pos de la actividad extractiva en Chile, y su posterior mercantilización y comoditización dentro del sistema social y económico chileno, ${ }^{3}$ Al cruzar la información primaria y la secundaria, daremos cuenta de la configuración institucional y legislativa que legitima un modelo social del agua que atenta contra los territorios y cualquier forma de vida en ellos. En particular, se trata de una política del agua que puso en crisis a las comunidades y culturas locales asociadas a la vida agro-pastoril, ampliamente expandida en Chile y que hoy se encuentra en extinción.

\section{Las resistencias a la colonización del agua en Chile y Latinoamérica}

En las últimas décadas, las regiones de Centroamérica y América del Sur han sido protagonistas de un crecimiento exponencial de conflictos por el agua. Esta realidad se explica por la expansión de las fronteras extractivistas asociadas a la actividad minera-energética, agroexportadora y forestal, principalmente, que ha consolidado a estas regiones en su posición de proveedoras de materias primas en la economía global, al tiempo que ha acentuado las históricas relaciones de dependencia económica entre países del norte y sur. Esta dependencia ha sido leída desde el pensamiento y la crítica decolonial, y también desde la ecología política latinoamericana, como una nueva colonialidad de la sociedad y la naturaleza asociada a una matriz de dominación. Sus consecuencias se traducen en múltiples resistencias de comunidades y organizaciones, sobre todo indígenas y campesinas, que se oponen al deterioro y la destrucción de sus territorios (Ávila García, 2016, 20; Escobar, 2011,66; Alimonda, 2011, 23-28). En este sentido, no se puede privatizar ni mercantilizar el agua sin antes haberlo hecho con toda la naturaleza. Es un objetivo central del colonialismo y reforzado en el proyecto de modernidad, como bien lo describe Machado:

Bajo la continua y creciente expansión de la racionalidad mercantil, la episteme moderna -históricamente constitui- 
da mediante la progresiva articulación entre Ciencia, Estado y Capital-, se configurará como poderoso aparato semiótico-político de producción de la "verdad". A través de ella, Occidente emprenderá la conquista total del "mundo", partiendo en primer lugar, de la conquista/producción colonial de la entidad "Naturaleza": de la "naturaleza exterior", como tierra-territorio-recursos naturales, así como de la "naturaleza interior" en tanto sujetos-cuerpos-fuerza-de-trabajo, redefinidos ambos como objetos y medios de producción al servicio de la continua valorización del capital (Leff, 1994). Ciertamente, la conquista y producción colonial de la "Naturaleza" constituye la más fundamental de todas las fabricaciones coloniales. A través de [sic] ella, Occidente sentará las bases epistémicopolíticas de la apropiación desigual del mundo, y hará de ésta, un aspecto clave de su dominio político, de su configuración como centro hegemónico de la modernidad. Ahora bien, conviene precisar que ese complejo entramado de poder-saber resultante de la articulación histórica entre Ciencia-Estado-Capital, opera la producción colonial del mundo a través del [sic] continuado y diversificado ejercicio sistemático de la violencia. Es la violencia lo que sustenta, en última instancia, la productividad histórica y la eficacia práctica de esa episteme moderna. La producción colonial del mundo acontece a través de [sic] la violencia; es ésta [sic], el medio de producción por excelencia del colonialismo/colonialidad (Machado Horacio 2010, 146).

No obstante, se trata de un modelo resistido en diversas comunidades y territorios como en Bolivia, con la llamada guerra del agua, que nacionalizó dicho elemento y rompió con los proyectos de privatización impulsados durante el gobierno de Gonzalo de Losada en el 2003, reforzando las ideas de gestión comunitaria del agua que ancestralmente habían desarrollado comunidades 
4. Este proyecto, firmado por 12 países de la región, estará detrás de parte importante de los actuales proyectos de construcción y crecimiento de puertos logísticos, nuevos corredores bioceánicos y el desarrollo de múltiples conectores para el desarrollo minero-energético en regiones centro y sudamericanas como el canal de Panamá, la Amazonía y el Área Andina. indígenas Aymaras y Quechuas. En Argentina, producto de la contaminación del Río de la Plata por la empresa transnacional Suez y de la deficiente gestión de las aguas sanitarias, se generó una desobediencia civil en comunidades que se opusieron a pagar por los servicios; así logró el Estado recuperar las aguas sanitarias (Ávila-García, 2016, 21; Porto-Gonçalves, 2006, 15). En México, entre tanto, el agronegocio generó una depredación de los ecosistemas, de los acuíferos y de otras fuentes de aguas en la Comarca Lagunera y el Bajío Guanajuatense, los cuales afectaron la calidad de las aguas y, en consecuencia, la salud de las personas, quienes enfrentaron al Estado mexicano en instancias internacionales (Ávila-García, 2015, 25). Merlinsky registra el caso de contaminación del Riachuelo en Argentina y muestra la naturaleza política de los conflictos por la contaminación del agua invisibilizada e institucionalizada, que gracias a la agencia de las agrupaciones y los colectivos impusieron el tema en la agenda pública del Estado argentino (Merlinsky María Gabriela, 2013, 28).

Desde la geografía crítica, el análisis se ha centrado en el proceso de despojo acelerado experimentado en la década de los años 80 , promovido por organismos multilaterales como el Banco Mundial (BM), el cual ha consolidado un modelo capitalista centrado en lo que Harvey define una acumulación por desposesión. El desarrollo desigual de los territorios, así como las trasformaciones geográficas y sociales radicales generadas por la transnacionalización y financiarización de la economía (Harvey 2005,137), han dado paso a la emergencia de una ecología política latinoamericana del agua, cuya crítica se dirige a la transformación del agua en un commodity (Ávila-García 2016, 21; Porto-Gonçalves, 2006, 18). A partir de su configuración como tal, se ha legitimado un sistema que reproduce las desigualdades en el acceso, la distribución, la calidad y la disponibilidad del líquido, lo mismo que las inequidades sustanciales en los sistemas de administración y gestión, que han privilegiado los usos productivos del agua cual recurso o bien económico en el marco de una privatización y mercantilización creciente en la región. Se trata de un escenario global que ha incentivado una regulación flexible del agua, compatible con los esfuerzos de globalizar la economía mundial a través de diversos tratados de libre comercio y de proyectos de infraestructura macro-regionales tales como el Proyecto de Integración de la Infraestructura Regional Sudamericana (IIRSA). ${ }^{4}$ Los cambios legislativos desplegados en toda nuestra región a lo largo de la últimas tres décadas reforzaron la comoditización del agua y acentuaron su carácter privado y uso productivo, concordante con la expansión del modelo exportador primario que va a caracterizar la década de los años 90. Los casos de Chile (1981) y México (1992) vendrían a ser los primeros ejemplos de privatización del agua, cuya base se asentó en el cambio de tenencia de la tierra y, en particular, en la separación de la tierra y el agua por medio de la legislación existente. Estas acciones, a su vez, crearon las bases para la construcción de mercados de aguas, fundamentos que aceleraron los procesos de crisis actuales en torno al acceso y la disponibilidad del agua, negando al mismo tiempo las dimensiones culturales, los usos rituales y las prácticas de irrigación históricamente encarnadas en las formas de vida y cosmovisiones indígenas y campesinas. 
Se instauró una comprensión neoliberal en torno al agua, que promovió una mirada técnica y burocratizada respecto de esta, sustentada en su control, administración y gestión.

Así, desde un discurso económico, se despolitizaron las dimensiones sociales y culturales del líquido en cuestión, privilegiando su uso extractivo, asociado al modelo exportador que negó y violó derechos culturales fundamentales protegidos por las legislaciones de los años 90 (particularmente el Convenio 169 de la OIT y la Ley Indígena). En este sentido, parte de la literatura especializada reforzó esta mirada del agua como recurso, invisibilizando la crítica dirigida a la lógica y racionalidad capitalista de la naturaleza.

Los conflictos por el agua, eje de disputas entre diversos actores con usos y valoraciones diversas (Orlove y Caton, 2010, 403; Strang, 2004, 51), revelarán dimensiones nuevas de racismo e injusticia social y ambiental (Castillo Gallardo, 2016, 90; Merlinsky, 2013, 31; Martínez Alier, 2004, 27), cuyos sufrimientos serán testimoniados por la etnografía reciente (Auyero y Swistun, 2008 , 38). Paralelamente, aparecerán trabajos asociados al agua como un derecho humano, en particular desde su reconocimiento en el 2000 por la Organización de las Naciones Unidas (ONU) (Bakker 2007,433; ONU, 2002). En esa línea, los trabajos de redes globales como Waterlat, contribuirán a analiza las dimensiones de violencia y las crisis democráticas vinculadas a la desaparición del agua como un bien público y su legitimación progresiva como bien económico (Castro, 2016, 17) .

No obstante la fluidez y transparencia del agua, le otorgan una particular peculiaridad para su control, generando visiones y comprensiones que, mediante prácticas culturales, resisten y dificultan su completa apropiabilidad. Los problemas del poder en la distribución y en el acceso al agua han sido especialmente puestos en relevancia en los debates de la ecología política latinoamericana, donde convergen visiones indígenas, comunitarias y sociales con diversos niveles de representación, racionalidades y prácticas (Castillo, 2016, 91; Bustos, Montt y Barton, 2015, 10; Gudynas, 2015, 141; Porto-Gonçalves y Leff, 2015, 73).

Entre estas lecturas y perspectivas destacan las que han emergido de los pueblos andinos con el buen vivir y la ética del cuidado, las cuales contribuyen de especial manera a una mirada crítica y reflexiva latinoamericana sobre los procesos de colonialidad que se perpetúan en los modelos del mal desarrollo y en la expansión de los extractivismos durante las últimas décadas en nuestro continente (Svampa y Viale, 2014, 363; Acosta, 2009, 27).

Entre los aspectos que sus trabajos resaltan, dan cuenta de una nueva colonialidad del poder y del saber, asociados a la naturaleza y el medioambiente, que toman fuerza con la expansión del neoliberalismo en las últimas cuatro décadas (Lander, 2000,13-14); en particular, la continua dependencia económica asociada a la exportación de commodities en contextos de desarrollos desiguales. Esta colonialidad presenta una nueva cartografía global, que abre nuevos espacios para el vaciamiento y despojo territorial (Grinberg, 2012 , 20). Gran parte de esa geografía desigual impuesta por el capitalismo 
tardío en las décadas de los años 80 por las agencias multilaterales, será reforzada debido al neocolonialismo instaurado en la década siguiente con la serie de tratados regionales de comercio e infraestructura destinados a garantizar el proceso de acumulación por desposesión; en particular, los firmados para América del Norte (TLCAN), el ALCA, el Plan Puebla y el Proyecto Mesoamérica, entre otros. Estos, en su mayoría, significaron una consolidación de la expansión de las fronteras extractivistas y un progresivo despojo de las condiciones materiales de las comunidades y territorios destinados a una nueva fase de inserción subordinada en la economía mundial (Ávila-García 2015, 20).

No obstante, las organizaciones socioambientales y comunidades están replanteando su relación con el territorio en un contexto de capitalismo avasallante, generando nuevas alternativas y nuevos conocimientos (Svampa, 2011, 181-215; Escobar, 2011, 61-92). Estas ecologías de saberes propuestas por estas prácticas colectivas (De Souza Santos 2012, 24-25) son defendidas desde una nueva reflexión sobre la democracia y el ejercicio de una ciudadanía ambiental antes desconocida (Gudynas, 2009, 66). De este modo planteamos la eco-geo-política desde los territorios como una propuesta analítica y un concepto que emerge colaborativamente, en particular en una perspectiva que surge de la geografía social en el pensamiento de Porto-Gonçalves y su propuesta de geograficidad del agua (Porto-Gonçalves, 2006, 19).

Consideramos que la geografía de las resistencias relevadas por la ecología política desde los territorios, planteada en los trabajos de Porto-Gonçalves, así como los propios trabajos de las organizaciones ambientales como el caso de las contribuciones de Rodrigo Mundaca en Chile, representan una nueva etapa de sistematización y reflexión desde las experiencias latinoamericanas que hemos dado en llamar eco-geo-política del agua desde los territorios. Deseamos mostrar la convergencia de propuestas desde el ambientalismo, la ecología política, la geografía crítica y el trabajo y producción de saberes comunitarios sobre el territorio que está siendo construido en diversas regiones, donde las resistencias y experiencias han permitido un desarrollo epistémico.

Dicha categoría se propone, del mismo modo que hemos descrito en trabajos anteriores: como una racionalidad alternativa que emerge en los intersticios y las resistencias al neoliberalismo. Ellas se presentan a su vez como una ruptura con el colonialismo ambiental que ha perpetuado una continuidad del modelo primario exportador asociado a la región latinoamericana y su actual inserción subordinada a la economía global. Se presenta esta geografía de las resistencias como una racionalidad colectiva que está reactivándose en diversos puntos, como lo muestran los casos de Bolivia y Argentina ya mencionados, y el de Petorca en Chile -entre otros múltiples ejemplos; es, por lo tanto, una apertura imaginativa a las narrativas dominantes del desarrollo y el progreso.

En tal contexto, es relativamente sabido que el modelo de gestión del agua en Chile es uno de los más privatizados y mercantilizados del mundo (Budds, 
2012,168; Budds, 2004, 323; Bauer, 2003, 7). Esta verdad compartida tanto por quienes lo consideran un modelo plausible y replicable, y para quienes lo perciben como el principal motor de las desigualdades y los conflictos, confronta a una diversidad de imaginarios y cosmovisiones sobre la relación naturaleza y cultura. Para los primeros, dichos conflictos surgen de la sequía, el cambio climático y la naturaleza, mientras que para los segundos, en cambio, los conflictos se originan en la usurpación y el robo del agua, a propósito de la expansión de las fronteras extractivistas de la minería y el agronegocio (Mundaca, 2014, 53).

En este campo de disputas y batallas, los significados y valores sociales, políticos, culturales y económicos del agua emergen como un nuevo paradigma interpretativo de la sociedad chilena postdictadura. En particular porque con la legislación impuesta durante la dictadura militar, se aceleraron los procesos de privatización y mercantilización de los bienes naturales y, en particular, del agua (Prieto 2015, 139-140), la cual abrió paso a un mercado cada vez más cotizado para los diversos extractivismos desarrollados en Chile (en particular el minero, agroexportador y forestal). la estructura jurídica de la dictadura que potenció estos procesos se basa en a) el Decreto Ley 600 de Inversión Extranjera Directa de 1976, que significó la apertura a los capitales transnacionales; b) la Constitución Nacional de 1980, que consagró la propiedad privada como un derecho central del contrato social chileno; c) el Código de Aguas y d) el Código Minero de 1981 y 1982, respectivamente, los cuales operaron como dos fuentes de derecho privado sobre el territorio y reforzaron el uso productivo de los recursos como el agua y la tierra. Estos cuatro pilares configuraron el marco ideal para el modelo exportador iniciado durante la dictadura militar (1973-1989) y consolidado durante los gobiernos democráticos posteriores (1990 hasta ahora).

Figura 1. Mapa de la provincia de Petorca en la región de Valparaíso, Chile.

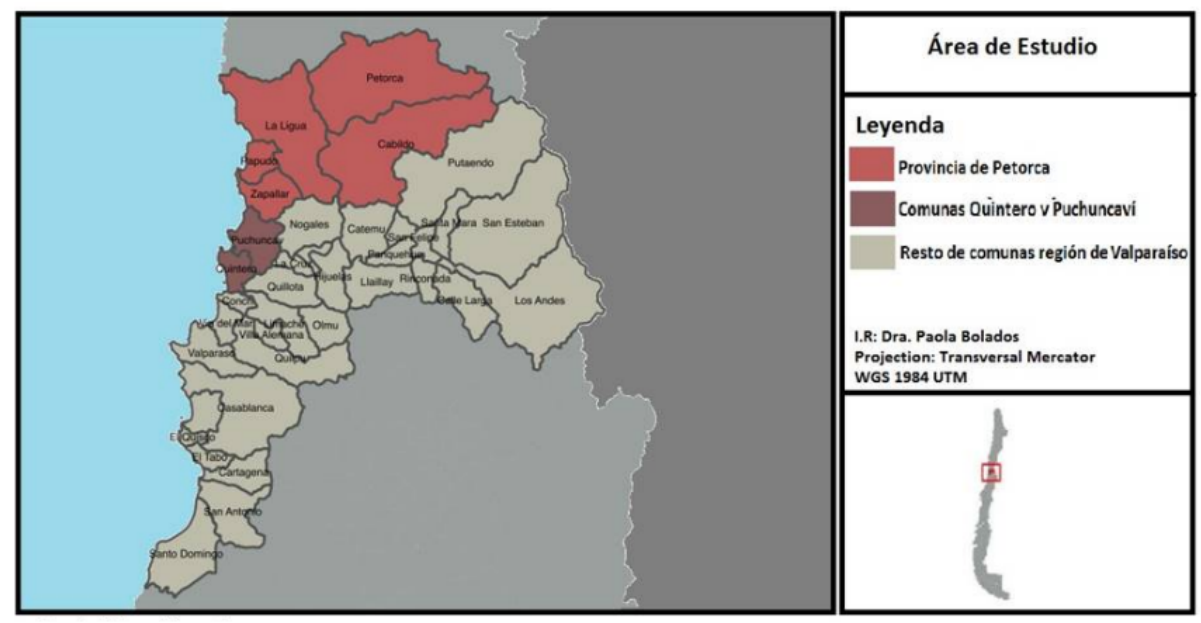

Elaboración propia 
En este marco, el Código de Aguas separó la tierra del agua y entregó derechos de aguas permanentes y a perpetuidad, lo que contrarió, en muchos casos, los derechos de terceros y las capacidades ecológicas de las cuencas. Consecuentemente, recién retornada la democracia en Chile, se comenzaron a observar las primeras crisis en las aguas superficiales durante la década de los 90, y una década después, en las aguas subterráneas (Budds, 2012, 173).

\section{El despojo de la tierra que antecedió al despojo del agua}

El caso de la provincia de Petorca -en particular en las comunas de Petorca, La Ligua y Cabildo en la Región de Valparaíso, mostraron una realidad compartida en varios territorios: las actividades extractivistas y sus demandas de aguas habían generado desde los años 90 una crisis sin precedentes para el acceso al agua. El desastre ecológico y social generado por el sobreotorgamiento de derechos de aguas subterráneas en ese periodo demostró dos mecanismos centrales en la política privatizadora del agua: el factor de incertidumbre en relación con los datos existentes sobre los derechos otorgados o bien la reinterpretación de datos en algunos de los estudios realizados dio pie

5. En el 2012, el entonces Director General de Aguas, en una reunión de la Comisión Económica para América Latina (CEPAL) sobre los avances en la implementación del modelo de Gestión Hídrica de Cuencas Integradas (IWRM), reveló que en Chile la DGA para ese entonces poseía información de solo $17 \%$ de derechos catastrados. En esta misma reunión y en el marco de otra investigación, uno de los investigadores de este artículo conoció a algunos miembros de MODATIMA, quienes se hicieron presentes en ese encuentro e irrumpieron en la actividad luego de la intervención del ministro de Agricultura en ejercicio. a los debates en torno a la escasez, ${ }^{5}$ Junto a ello, el discurso de la sequía comenzó a desplegarse en el mismo lapso y permitió, entre otras acciones, justificar la entrega de financiamiento público a los grandes agricultores para proyectos de infraestructura de aguas mediante la Comisión Nacional de Riego (CNR). Se consolidó así un nuevo sistema de concentración de la tierra y ahora el agua estaría en manos de privados (agroexportadoras), financiado con recursos del Estado que legitiman un sistema de mercado que consagra la propiedad privada y la creación de un mercado de aguas único en el mundo.

Empero, tales procesos no se produjeron sin una complejidad histórica anterior, relacionados a la tenencia de la tierra y a los procesos de variaciones normativas asociadas a esta materia, como la Reforma Agraria iniciada en 1967. En Chile, el conflicto por el agua en las comunidades de Petorca no puede entonces separarse del problema histórico de la tierra. Un conflicto de concentración que se consolidó en los siglos XIX y XX, cuando el campo experimentó profundas transformaciones en su organización. En el caso de Petorca, las haciendas de los Valles de la Ligua y Cabildo tendrían una larga historia de concentración que se había originado en el alero de las haciendas y los fundos de las familias aristocráticas de Santiago. En ellas se desarrollaría una larga conformación cultural, ampliamente expandida en Chile, llamada la sociedad colonial-hacendal, heredera de la colonia pero reforzada durante la república. En ella se consolidará lo que Bengoa define como la comunidad de desiguales, cuya base y estructura económica se vendría a sostener en la división entre patrones y peones (Bengoa, 2015, 24). En el caso de Petorca y sus valles, al igual que los sectores precordilleranos, aunque existan diferencias en cada caso, nos encontraremos con el elemento común de la expansión de un poder económico agrícola que durante siglos ha alter- 
nado con el desarrollo de una mediana y pequeña minería del oro, promoviendo la llegada de grupos de mineros que darían origen a las primeras organizaciones mineras y luego campesinas. Estas últimas, sin embargo, tomarán un rol activo a partir de la reforma agraria de 1967, que facilitó la organización campesina y, además, comenzó a desincentivar la concentración de la tierra (Calderon y Fahrenkrog, 2012, 30; Garrido, Guerrero y Valdés, 1988). El proceso maduró e irrumpió con la llegada de la Unidad Popular en 1971, cuando, mediante cooperativas, se intentó romper esta estructura social, y una parte importante de los trabajadores consiguen convertirse en los dueños de los antiguos terrenos de sus patrones.

Las dificultades para la organización colectiva y la fuerza de la estructura de las clases dominantes -consagrada aún más por la presencia de la iglesia en Petorca, generaron rápidamente que las cooperativas de los campesinos se debilitaran. A su vez, en este fracaso también operó la falta de conocimiento del territorio por parte de los organismos políticos del Estado, que tenían una historia vinculada a la ganadería y criancería en los sectores precordilleranos. De esta historia, quedan solo los viejos corrales que hoy son utilizados para guardar madera y los productos asociados a la nueva actividad agroexportadora.

El proyecto socialista en Chile fue interrumpido abruptamente con la dictadura militar y su plan político neoliberal. En ese contexto, comenzó la política de parcelación, también conocida como la contrarreforma implementada por la dictadura, la cual transformó paulatinamente la idea de derechos de tierras colectivas a derechos de tierras individuales. De comuneros pasaron a ser parceleros y luego de parceleros a campesinos sin tierra (Bolados García, 2016, 118). Esto ocurrió en el transcurso de los años 80 y se profundizaría en los años 90, cuando la política agroexportadora impulsada en esta región trajo aparejada, como contracara, la crisis del agua que presionó a muchos campesinos y pequeños agricultores a vender los terrenos recuperados en la reforma agraria.

Una nueva concentración de la tierra se produjo en dos décadas (1990 y 2000), y en la que se incorporaron nuevos actores en torno a la fiebre del oro verde: el cultivo de la palta (aguacate). El territorio, proveedor histórico de cereales, se dedicaría al monocultivo de la palta, en el marco de una política exportadora incentivada desde el Estado. Durante aquel tiempo, la región se convirtió en la exportadora mundial de casi $60 \%$ de este fruto. ${ }^{6}$ La actividad se expandió a zonas no tradicionales de cultivo o denominadas lugares de secano (Murray, 1997, 48); se reconvirtieron en tierras para la producción de paltas a través de complejos sistemas de riego. Tal expansión aceleró al abandono de la criancería o ganadería de caprinos, que hasta entonces era una actividad tradicional compartida entre los sectores precordilleranos del Norte Grande y del Norte Chico. Fue un despojo cuyas consecuencias culturales se expresaron en los conflictos y las denuncias que emergieron hacia mediados del 2007 y que tendrían su punto más alto durante el 2012.

Este fue un período de inflexión en lo que respecta a la desnaturalización del neoliberalismo en Chile: irrumpieron un sinnúmero de movilizaciones sociales

6. La actividad tuvo un crecimiento sostenido hasta la segunda mitad del 2000, cuando la demanda de palta desde EEUU experimentó una baja sustantiva. Sobre los datos de exportación de la palta, ver en el Catastro Frutícola de ODEPA- CIREN Región de Valparaíso. 2014. 
7. Estas ideas fueron principalmente desplegadas por los gobiernos de Eduardo Frei Ruiz- Tagle, quien firmó gran parte de los acuerdos de libre comercio para desarrollar la política exportadora; luego, en los gobiernos socialistas de Ricardo Lagos y Michelle Bachelet, se dispararon los otorgamientos de derechos de aguas subterráneas y se privatizan las aguas sanitarias.

8. Cabe señalar que el abogado defensor del exsenador de la Democracia Cristiana contrató los servicios jurídicos del exdirector de la Dirección General de Aguas, Rodrigo Weisner, con quien logró ganar la demanda y dejar con medidas de arraigo nacional y firma mensual al reconocido dirigente de MODATIMA, Rodrigo Mundaca.

9. Cabe señalar que los informes que dan cuenta de estas denuncias y sus respectivas investigaciones fueron el informe El Derecho al agua como un Derecho Humano: El caso de la Provincia de Petorca (2013, 263 y 264); y el informe Misión de Observación Provincia de Petorca $(2014,16)$ y ambientales en el norte, el centro y el sur del país, que desmitificaron en parte el imaginario extractivista y exportador introducido por el régimen militar y consolidado por los gobiernos democráticos posteriores. ${ }^{7}$ En ese escenario, la denuncia del dirigente Rodrigo Mundaca sobre la usurpación de aguas en la provincia de Petorca, inició un proceso de crítica al, hasta ahora, exitosamente exportado modelo chileno de aguas. La denuncia se planteó en un programa televisivo de alcance nacional, el cual dio pie a una demanda por parte del denunciado, el exministro demócrata cristiano, Edmundo Pérez Yoma. $^{8}$

En ese contexto, en el 2014, surgieron los informes del Instituto de Derechos Humanos y de la Universidad Diego Portales, que señalaban los casos de las empresas agrícolas y titulares de derechos de aguas denunciados y judicializados mediante algunos recursos de protección interpuestos por las organizaciones del territorio. El Instituto de Derechos Humanos, a partir de una misión de observación, constató la existencia de drenes ilegales construidos sin autorización de la Dirección General de Aguas (DGA), lo cual dio paso a la creación de una Comisión de Recursos Hídricos en la Cámara de Diputados. ${ }^{9}$

En el mismo año, el dirigente Rodrigo Mundaca, secretario del Movimiento de Defensa del Agua, la Tierra y el Medio Ambiente (MODATIMA), publicó el libro La Privatización de las Aguas en Chile. Causas y Resistencias. El centro de la crítica se dirige al modelo agroexportador en tanto destruye los ecosistemas y las economías locales, generando nuevas formas de dependencia y empobrecimiento de los territorios. Un modelo que significará que las comunidades se queden sin agua para el consumo y para el riego, generando una competencia desigual por obtener no un recurso natural como sostienen el Estado y las empresas, sino un bien común -en palabras de los miembros de MODATIMA, y por el cual se involucran derechos humanos fundamentales, entre ellos, el derecho humano al agua (Mundaca, 2014, 68).

En tanto, la DGA, entidad estatal a cargo de administrar la política de aguas en Chile, después de la tardía reacción de las administraciones anteriores y la gravedad de los hechos, intentó resarcir el drama en torno al agua en la provincia de Petorca, suprimiendo los derechos provisionales a varios de estos denunciados. Estos se otorgaron después de casi 10 años de declarada la zona agotada para entrega de derechos de aguas subterráneas, y casi 15 luego de haber sido declarados agotados los Ríos de Petorca y la Ligua, las principales fuentes de agua de la zona. Así lo recuerda un campesino de Cabildo y miembro de MODATIMA:

Fuimos a Santiago a la mesa del agua de los diputados y ahí planteamos; la cuestión es que salió porque estamos en zona...una que estamos en zona de catástrofe hídrica; la cuenca está agotada desde el 2004 y no me acuerdo si fue el 2006 o 2007. No, en el gobierno de Piñera fue que quitaron a todos los que tenían litros inscritos provisorios; 
son como 1.170 litros; a todas las grandes empresas agrícolas tenían litros provisorios. Entonces, peleamos esa parte nosotros; nos juntamos un grupo de dirigentes y en el gobierno de Piñera les quitaron esos litros provisorios a todas las empresas agrícolas, porque estaban perjudicando mucho a las APR y resulta que llevaba más de un año la presidenta Bachelet y todavía no los quitan. Entonces, fuimos con los dirigentes de MODATIMA a la mesa del agua de la Cámara de diputados a Santiago la semana pasada y planteamos la situación po' de que se está viviendo, que no han quitado los derechos provisionales, que debieran haberlos quitado. Hay gente que tiene derechos provisionales y está vendiendo agua; hay gente que no tiene ni litros inscritos en la Dirección General de Aguas - $V$ región- y venden agua. Entonces, están lucrando con un bien de uso público. Entonces, están perjudicando aguas abajo a todos los comités porque ahí donde venden agua arriba están perjudicando al comité mío. La Viña, La Vega, porque en Pililén hay un particular que vende... Le vende, chorreras de camiones salen con agua ahí, le vende a ESVAL (Empresa sanitaria de Valparaíso), pa' las mineras; y aquí en el puente San Lorenzo, ahí es peor porque salen 30, 40 camiones diarios pa' abastecer a ESVAL y también están lucrando porque el gallo no tiene ni un litro inscrito y el mismo gobierno le compra agua. Entonces, no sé cómo entiendo al gobierno ahí y eso reclamamos en Santiago (extracto de entrevista a pequeño agricultor de Cabildo, julio del 2015).

Esta crisis en el gobierno de derecha de Sebastián Piñera (2010-2014) intentó ser resuelta por la reactivación de la política hídrica global conocida como Gestión Integrada de Recursos Hídricos -Integrated Water Resource Management IWRM-, la cual fue promovida principalmente por organismos interna- 
cionales como el BM y la Comisión Económica para América Latina y el Caribe (CEPAL).

Aunque se trataba de un esfuerzo institucional por atender a la crisis del agua a nivel global y planteaba una propuesta integral en torno a las cuencas como formaciones socionaturales fundamentales para su gestión y administración, la iniciativa no se hacía cargo de las desigualdades ya establecidas, y mucho menos de las limitaciones y falencias de las legislaciones que las habían consolidado. De hecho, esta iniciativa que surgió de los Acuerdos de la Conferencia de Dublín en las reuniones previas a la Cumbre de Río de Janeiro, en su último y más polémico punto consagró el agua como un bien económico (Bauer, 2003, 7; Orlove y Caton, 2010, 408-409).

A pesar de que se planteaba como un programa que incorporaba la participación activa de los usuarios, esta impulsaba y legitimaba un sistema de participación regida por una lógica mercantil de acceso al agua. Vale decir que las Juntas de Vigilancia y formas de organización participativas se entienden en relación con la cantidad de derechos de aguas otorgados. A más derechos de aguas, más participación y administración de la misma. Con este modelo, se consagró a nivel internacional la desigualdad frente al acceso y la administración, así como la facilidad para los usos extractivistas, en particular por medio de los derechos de aguas no consuntivos disponibles para proyectos energéticos hidroeléctricos (Prieto, 2015, 152).

En consecuencia, quienes requerían expandirse ya no podrían solicitar más derechos de aguas, por lo que se trataba ahora de conseguir comprar aguas en el mercado de aguas. El Estado, a fin de equiparar esta desigualdad, desarrolló líneas de trabajo en proyectos del Instituto de Desarrollo Agropecuario (INDAP), los cuales operaron como un modelo paliativo y subsidiario para medianos y pequeños productores.

Asimismo, se retomaron antiguos proyectos de embalses que se diseñaron en la década de los años 60 y que se presentaron como los salvavidas de la tragedia. No obstante, el desarrollo de estos embalses fue un elemento más de discordias en el territorio, puesto que en torno a ellos se sembró la duda respecto de quién los administrará, y quiénes y cómo se distribuirán esas aguas acumuladas. Por ende, los pequeños agricultores serían doblemente afectados, ya sea por el sobreotorgamiento de derechos de aguas y por las medidas de restricción para la regulación y entrega de nuevos derechos (que los discriminaba por no contar con los recursos económicos para competir en este modelo mercantilizado del agua).

Como promesa de gobierno, se retomó la discusión históricamente dilatada de la Reforma al Código de Aguas (17 veces puesta en la agenda legislativa desde el retorno a la democracia). La discusión legislativa podría demorar casi todo el, entre otros motivos, por las presiones de la Asociación Nacional de Agricultura (SNA), que la definirán como una reforma expropiatoria. No obstante, entre los cambios relevantes del discurso que se pueden observar a nivel del Estado, sería la actual posición del área jurídica de la DGA la que, asumiendo que al 2012 solo ha catastrado 17\% de los derechos de aguas en 
Chile, se abogaría por la postura de que ha habido un error de interpretación del Código de Aguas respecto de la propiedad del líquido. ${ }^{10}$ Así, se señala que los derechos no implican perpetuidad como había sido interpretado hasta ahora, sino que la DGA, a cargo de la administración del agua, puede reasignar derechos según los criterios técnicos que defina (Sesión de Comisión de Recursos Hídricos, febrero del 2017).

La conciencia de las crisis en torno al agua en la provincia de Petorca, que se comenzó a agudizar en la década de los años 90, podría recrudecerse aún más en las décadas del 2000 y del 2010, lo que mostraría la racionalidad económica y política de la escasez y la sequía. Para ejemplificar la situación, el aumento del caudal asignado para el período 1995-1999 se explicó por la convergencia del aumento en 2,6 veces de la cantidad de derechos concedidos con respecto del periodo inmediatamente anterior -se pasó de 86 derechos entregados entre 1990 y 1994 a 222 en el quinquenio 1995-1999; pero sobre todo por el aumento de los caudales promedio anuales entregados, los que entre 1990 y1994 sumaron 866 l/s, lo que equivaldría a un aumento a $7.727,6 \mathrm{l} / \mathrm{s}$ en el quinquenio 1995-1999

Figura 2. Caudal promedio anual concedido en derechos de agua en la provincia de Petorca entre 1960 y $20 \mid 7$ (I/s por quinquenio)

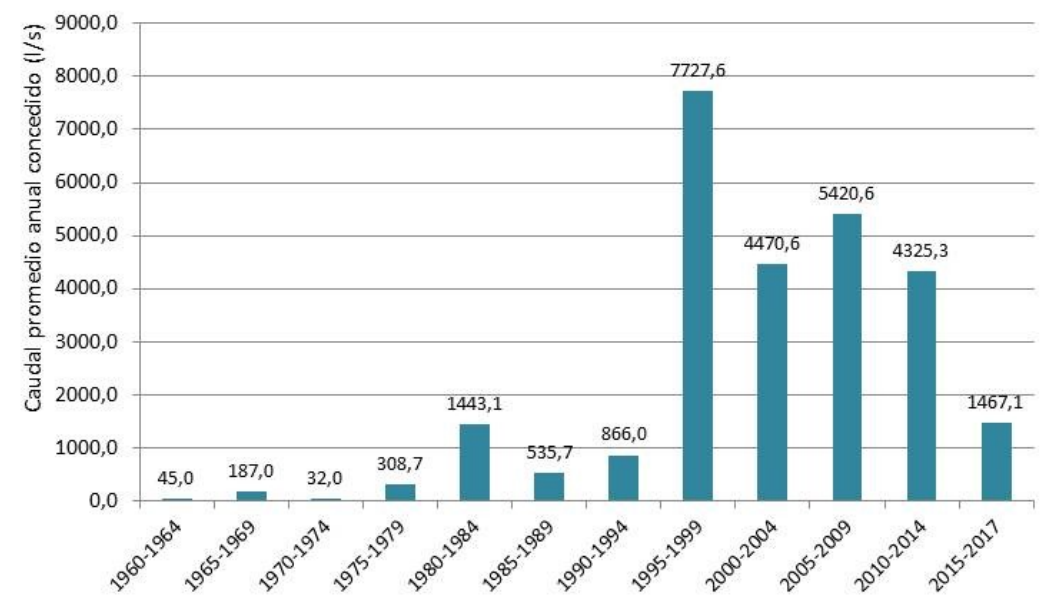

Elaboración propia a partir de lista de derechos de agua concedidos en la V Región (DGA 2017)

El caso del aumento de extracción de agua en el quinquenio 2005-2009, se explicó por la quintuplicación de derechos otorgados respecto del periodo inmediatamente anterior: se pasó de 317 derechos concedidos entre 20002004, a 1.555 entre el 2005 y el 2009 (con un caudal acumulado de 5.420 I/s). Es el período de más entrega de derechos de aguas subterráneas, por lo que se desatarán los conflictos más agudos en la provincia de Petorca (Figura 3$).{ }^{11}$
10. Esta discusión se dio en el marco de la Comisión Especial sobre Recursos Hídricos Desertificación y Sequía de la Cámara de Senadores, sesión 14/03/2017. Disponible en http://www.senado.cl/appsen ado/index.php?mo=comisiones $\& a c=$ sesiones_celebradas\&idc omision $=1009 \&$ tipo $=3 \& a n o=201$ $7 \&$ comi_nombre $=$ Especial\&idse sion $=11456 \&$ fecha $=14 \% 2 \mathrm{~F} 03 \% 2 \mathrm{~F}$ 2017\&inicio=09\%3A30\&termino $=12 \% 3$ A35\&lugar=Sala\&listado $=2$ 
Figura 3. Número de derechos de agua concedidos en la provincia de Petorca entre 1960 y 2017 (por quinquenio)

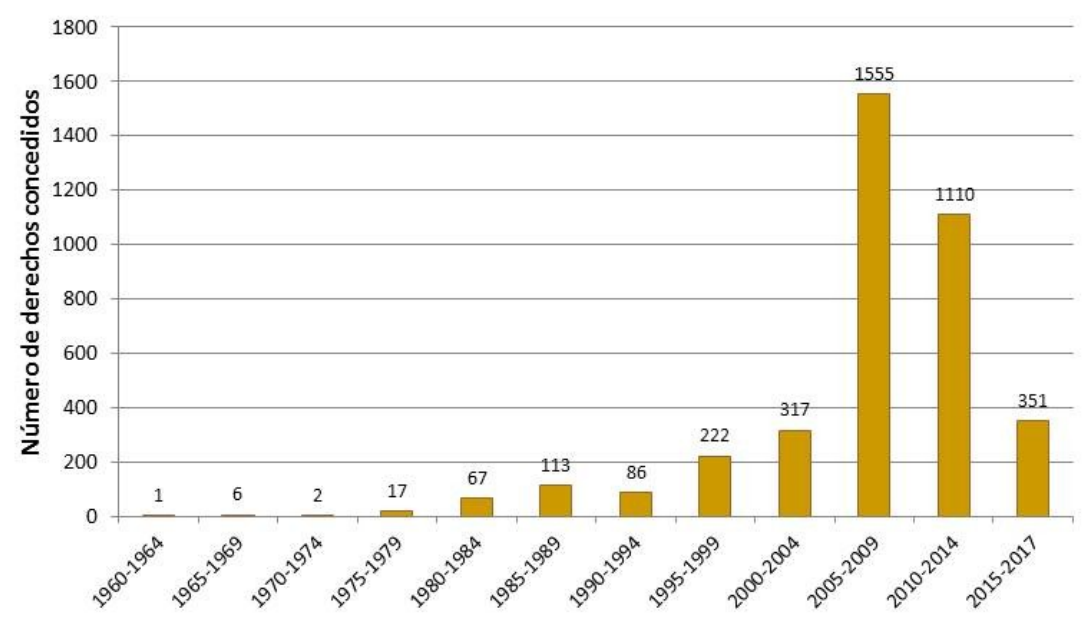

Elaboración propia a partir de derechos de agua concedidos en la V Región (DGA 2017)

El modelo de distribución del agua basado en la incertidumbre de la información sobre derechos inscritos, así como la negación del sobreotorgamiento de derechos de aguas en contextos y territorios ya declarados agotados, operaron como dos imaginarios que marcharon de la mano entre los discursos del Estado y las empresas, en contraposición a las denuncias de las comunidades y organizaciones de la zona. En particular y como bien describe Budds, las diferencias entre grandes agricultores, pequeños y nuevos no fue advertida, y mucho menos, la capacidad económica y jurídica requerida para regularizar el proceso de inscripción de aguas. La consecuencia fue que el criterio de asignación de aguas por la DGA reforzó esta estructura social y les otorgó más a quienes más recursos y capacidad de adquirir tecnologías y asesoría legal tenían, principalmente a los grandes y nuevos agricultores dedicados a la exportación de palta (Tabla 1). 
Tabla 1

Número de derechos y caudales concedidos durante el período 2000-2009 (sólo aquellos que concentran más de $100 \mathrm{l} / \mathrm{s}$ concedidos en el período)

\begin{tabular}{lcc}
\hline Nombre & $\begin{array}{c}\text { Total } \\
\text { Derechos } \\
\text { Concedidos }\end{array}$ & $\begin{array}{c}\text { Total Caudal } \\
\text { Concedido } \\
\text { (I/s) }\end{array}$ \\
\hline Asociación de Canalistas Canal Chincolco & 7 & $1.225,3$ \\
Sociedad Agrícola y Ganadera El Sobrante Limitada & 3 & 968,3 \\
Sociedad Agrícola Los Angeles de Cabildo Limitada & 9 & 700,0 \\
Agrícola Petorca S.A. & 26 & 252,1 \\
Sociedad Agrícola Los Graneros Limitada & 28 & 186,9 \\
Agrícola Altos de Polcura Ltda. & 2 & 154,0 \\
Agrícola Chacra San Pascual Limitada & 8 & 135,0 \\
Agrícola Olivos de Huaquen S.A. & 14 & 129,3 \\
Empresa de Obras Sanitarias De Valparaiso S.A & 3 & 125,0 \\
Agrícola San Juan Limitada & 9 & 121,5 \\
Agrícola e Inmobiliaria Los Altos De Zapallar Ltda & 9 & 121,0 \\
Agrícola San Lorenzo Limitada. & 6 & 120,6 \\
Sopraval S.A. & 9 & 118,4 \\
Esval S.A. & 6 & 117,0 \\
Agrícola Pullacon Limitada & 16 & 111,0 \\
Agrícola Paltuncho Ltda & 45 & 108,0 \\
Agrícola Cóndor Limitada & 4 & 104,3 \\
\hline
\end{tabular}

En particular, esto hizo una crisis en el 2004 cuando se realizó una de las principales regularizaciones de derechos de aguas. En ese contexto, la DGA, para enfrentar el exceso de demanda, incorporó nuevas variables que modificaron los resultados del estudio hidrológico, con lo cual logró triplicar el caudal supuestamente disponible (Budds, 2012,177). La geógrafa Jessica Budds describe el proceso de la siguiente manera:

A pesar de estas limitaciones, la DGA adoptó los resultados de la evaluación como fundamento para la distribución del agua subterránea (DGA 2004a). Se adoptó la cifra de 1.547 litros por segundo desde un "escenario" para representar la cantidad de agua real que era disponible para la asignación de nuevos derechos. Sin embargo, 
esta cifra solo fue suficiente para otorgar los derechos de agua que habían sido solicitados hasta octubre de 1996. Visto que esto dejaría la mayor parte de la demanda insatisfecha, la DGA incorporó tres factores para poder incrementar la cantidad de agua disponible: i) el agua no utilizada en la cosecha y que era devuelta a la fuente (caudales de retorno); ii) fugas del suministro de agua potable; y iii) derechos "provisorios" en un 25 por ciento del total de derechos de agua subterránea otorgado, aun cuando "ninguno" de estos estaba incluido en el modelo. La nueva cifra, de 5.542 litros por segundo, era suficiente para otorgar casi todos los derechos de agua que se habían solicitado hasta noviembre del 2003, aunque el escenario del modelo solo incluía derechos de agua otorgados y nuevas solicitudes hasta marzo de 2001 (Budds 2012, 178)

Así se respondió a la demanda de los grandes y nuevos agricultores, quienes en su mayoría concentraron el agua para las agroexportadoras, generando un drama sin precedentes entre los pequeños agricultores, como lo reconoce un pequeño agricultor de Cabildo:

Es que hay mucha desigualdad y se ve mucha; no sé; el empresario grande, la actitud matonesca que tiene, que al más chico le pone la bota arriba. Entonces, MODATIMA y nosotros los dirigentes estamos viendo eso que está mal; no puede ser una sociedad; no vamos a llegar a ninguna parte si seguimos así. Entonces, se está denunciando a la gente que no tiene agua inscrita y está robando agua; que la DGA cumpla su función fiscalizadora y no lo hace; entonces, un chato que tiene 2 litros inscritos y saca 40 , aquí se está dando... Lo hemos denunciado con MODATIMA, al gobernador, con la DGA, ... por escrito y no se ponen las pilas y dicen: "No; tenemos un fiscaliza- 
dor para la zona" y ahora conversando con el Director Nacional en la Cámara de Diputados dijo: “Oiga: ahora este año nos contrataron 28 personas más como inspectores de la DGA a nivel país" po', pero nosotros queremos que pongan más aquí en la $\mathrm{V}$ región, que hay un inspector pa' toda la $\mathrm{V}$ región, entonces es pa'la risa. Aquí debieran tener sus 10 inspectores en esta región, no más que es la más conflictiva de la provincia de Petorca. Entonces, ha habido buenos inspectores aquí. Duran 2, 3 meses y los echan. ¿Por qué? Porque los grandes empresarios son parte del gobierno; entonces, empiezan a presionar y los echan; entonces, nosotros seguimos en desmedro en esa parte y los pozos, por ejemplo, todos los comités de agua potable se están secando... porque los pozos de 30,40 metros y ahora los pozos hay que hacerlos de 80, 90, 100 metros porque al empresario grande, al empresario agrícola se le seca un pozo de 30 metros [y] hace uno de 80; se le seca el de 80 [y] hace uno de 100 . Tiene recursos, pero y nosotros los dirigentes sociales, de las comunidades de agua, parceleros, no están los recursos. Hay que acudir... con proyectos asociativos al INDAP (Instituto Nacional de Desarrollo Agropecuario) y hay que reunir la gente, reunir las escrituras de cada uno que si tienen que tengan derecho a agua y que tengan tierra y si no en INDAP tampoco los pescan porque hay que demostrar que tenemos tierra y que tenemos agua. Pero el agua no la tenemos; hay que hacer el hoyo más profundo pa' tener el agua; entonces, ahí está la competencia con los grandes; entonces, los grandes hacen lo que quieren. Si aquí la plata manda, si con plata se compran huevos, como dice el refrán y es verdad (sí, po') eso está pasando; entonces el grande dice " hay que 
dividir para gobernar" y eso es verdad po' si el empresario grande divide, gobiernan a la pinta ellos. Mientras tengan los pollos de abajo dividíos, hacen lo que quieren. En cambio, si lo pollos se unen todos contra uno, cambia la cosa; entonces, eso es lo que impiden; le hacen la guerra a MODATIMA porque tratan de que no se unan a los pequeños, nosotros los dirigentes. Los empiezan a tratar por separado. ¿Para qué? Pa' dividirlos (extracto de entrevista a pequeño agricultor de Cabildo, febrero del 2015).

Mientras se continúa entregando derechos de aguas subterráneas en manos de agroexportadoras, irrumpe el negocio del agua potable. Las empresas sanitarias como ESVAL en la región de Valparaíso podrán cada vez menos asegurar la disponibilidad del agua potable en las áreas rurales de la región. De esta manera, emerge el negocio del agua potable gracias al municipio, el cual subsidia la falta del agua por medio de de la entrega de camiones aljibes (camiones repartidores de aguas). La compra y venta de agua en las comunas rurales de Petorca se constituirá en un paisaje social permanente y en una de las piezas claves del conflicto por el líquido. En esta intrincada red generada en torno al agua, actores políticos e intermediarios comienzan a lucrar con la escasez y la sequía. Los camiones aljibes entran como parte del paisaje en territorios históricamente dedicados a la agricultura y ganadería, produciendo un drama humano insospechado.

Poblaciones campesinas comienzan a resentir los impactos del marco jurídico de la dictadura en sus chacras. Tienen tierra, pero ya no son dueños del agua. Quienes lograron inscribirlas o bien hallar nuevas fuentes de abastecimiento, han encontrado que las napas subterráneas están secas. En la región de Valparaíso, hasta entonces es reconocida por los graneros y ruleros del campo (como se denomina a la producción de granos), estos tendrán que abandonar la agricultura y ganadería y, con el tiempo, muchos de ellos estarán forzados a vender sus tierras a empresas del agronegocio, principalmente.

\section{La productividad del conflicto por el agua en la Provincia de Petorca}

Nosotros hicimos una encuesta y una de las preguntas decía “¿Qué tenemos que hacer para recuperar el agua?" y $99.9 \%$ de la gente opinaba que había que seguir luchando. Habían [sic] algunos que decían que había que 
rezarle a Dios para que recuperara el agua. Había [sic] otros que decían que no la íbamos a recuperar nunca. Pero 99,9\% de la gente decía que había que luchar para recuperar el agua. Por lo tanto, nosotros no estamos muy lejos de lo que estábamos planteando; al contrario, estábamos hablando de algo que era correcto. Y para poder nosotros...para poder nosotros... eh.... poder determinar eso, hoy día [sic] tenemos informes que han hecho organismos... que no tiene que ver con nosotros (extracto de entrevista pequeño agricultor de La Ligua, febrero del 2015).

Figura 4. Caudales y derechos de agua concedidos entre 1960 y 2017 a los grupos familiares denunciados por MODATIMA

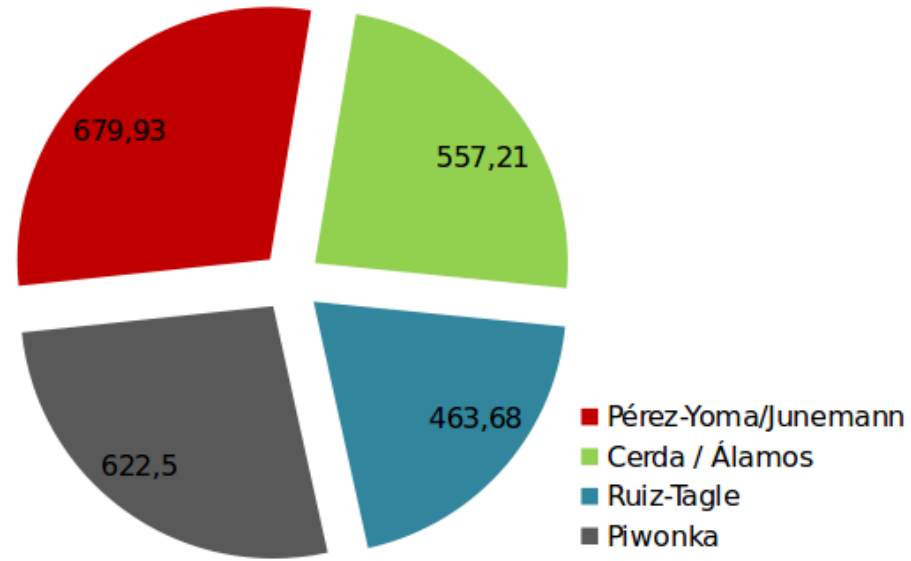

Fuente: Elaboración propia a partir de lista de derechos de agua concedidos en la V Región (DGA 2017)

MODATIMA se constituye como un catalizador de históricas demandas que entrecruzan antiguas historias de despojos y relaciones coloniales incrustadas en la estructura social de la provincia. Tales relaciones se rearticularon y profundizaron a propósito del imaginario agroexportador que se impondrá a partir de las transformaciones generadas por el código de aguas el año 1981. A partir de esta actividad, cuatro familias comienzan a concentrar tierras y luego derechos de aguas, los cuales tres de ellas, según las organizaciones del territorio, se señalan como las principales responsables de la crisis del agua. La primera familia que concentra agua está asociada al exministro Edmundo Pérez Yoma y su cuñado Osvaldo Junemann. En el registro de la 
12. Fue alcalde de Cabildo en 1960 y reelegido en 1963. Fue elegido diputado por la $5^{\mathrm{a}}$ agrupación departamental San Felipe, Petorca y Los Andes, en los periodos 1965-1969, 1969-1973 у 19731977. Fue

presidente de la Cámara de Dip utados de Chile

entre junio y julio de 1971

Vuelta la democracia, fue elegido diputado por el Distrito 10 para el período comprendido entre 1990 y 1994

13. Bajo las sociedades Agrícola Pullacón, Sociedad Agrícola Pullacón Limitada y Alberto Piwonka Zañartu.
DGA, aparecen con varias agrícolas y diversas empresas asociadas a estas con un total de casi 679,93 litros por segundo (que incluyen los derechos provisionales revocados en el 2014, pero que aún no se han hecho efectivos). Una de las empresas denominada Agrícola Cóndor, perteneciente al mismo grupo familiar, fue denunciada por MODATIMA, lo cual generó una contradenuncia y posterior condena hacia el dirigente Rodrigo Mundaca.

El segundo grupo lo constituye la familia Cerda Álamos (Ignacio Álamos Cerda) con casi 557,21 litros por segundo. Esta familia, de larga data en la provincia y cuyo padre Eduardo Cerda ocupará cargos políticos desde la década de los años 60 , fue la primera en expandir la agroindustria en la provincia. ${ }^{12}$ Tanto Pérez Yoma y Cerda están además asociados a uno de los partidos políticos más grandes del país y parte de la actual coalición gobernante de centro-izquierda -el Partido Demócrata Cristiano-.

El tercer grupo que concentra derechos de aguas en el territorio es la familia Ruiz Tagle, la cual está relacionada con uno de los partidos de derecha -la Unión Demócrata Independiente. Sus agrícolas Huingal y Los Ángeles fueron también denunciadas a causa de usurpación de aguas por MODATIMA (Chile Sustentable, 2012, 28 y 29). Por último y aunque no aparecen denunciados en los informes de derechos humanos antes señalados, Alberto Piwonka Zañartu e hijo tienen 622,5 litros por segundo en 51 derechos desde 1984 hasta el 2016 entregada por medio de la Agrícola Pullacón. ${ }^{13}$

\section{Tabla 2}

Caudales y derechos de agua concedidos entre 1960 y 2017 a los grupos familiares denunciados por MODATIMA, detallados por nombres de solicitantes asociados a cada uno

\begin{tabular}{llcc}
\multicolumn{4}{c}{ ASOCIADO A GRUPO FAMILIAR PÉREZ-YOMA/JUNEMANN } \\
Nombre de Solicitante & $\begin{array}{c}\text { Fuente } \\
\text { (cuenca) }\end{array}$ & $\begin{array}{c}\text { Caudal } \\
\text { L/s }\end{array}$ & $\begin{array}{c}\text { N } \\
\text { Derechos }\end{array}$ \\
Agrícola Cóndor & Río Ligua & 106,3 & 6 \\
Sociedad Agrícola Los Graneros Ltda. & Río Ligua & 314,5 & 62 \\
Agrícola La Loica Limitada & Río Ligua & 53,83 & 15 \\
Sociedad Agrícola Las Loicas Limitada & Río Ligua & 68 & 1 \\
Inmobiliaria Las Loicas S.A. y Otro & Río Ligua & 80 & 1 \\
Patricio Junemann Gazmuri y Otros & Río Ligua & 54 & 1 \\
Álvaro Luis Alberto Gazmuri Plaza & Río Ligua & 1,7 & 1 \\
\multicolumn{1}{c}{ ASOCIADO A GRUPO FAMILIAR CERDAIÁLAMOS } & 1 \\
Nombre de Solicitante & Fuente & Caudal & No \\
Eduardo Cerda García y Otro & (cuenca) & L/s & Derechos \\
Eduardo Cerda Lecaros & Río Ligua & 0,39 & 1 \\
Jaime Cerda García & Río Ligua & 10 & 1 \\
Jaime Cerda García y Otros & Río Ligua & 9 & 1 \\
Patricia Rebeca Lecaros Mackena & Río Ligua & 0,39 & 1 \\
Agrícola Pililén Limitada & Río Ligua & 2 & 1 \\
& Río Ligua & 33,5 & 9
\end{tabular}


Sociedad Agrícola Pililén Ltda.

Agrícola Santa María de Vitahue

Fernando Álamos Cerda

Ignacio Álamos Cerda

Ignacio Antonio Álamos Cerda

Fernando Álamos Cerda

Francisco Ignacio Álamos Jordán

Agrícola Chalaco

Valle del Norte S.A.

Francisco Javier Álamos Jordán

Pablo Alfonso Álamos Jordán

María Teresa Álamos Letelier

Agrícola Viento Norte Limitada

Agrícola El Silencio Limitada

Agrícola El Sobrante Ltda

Agrícola El Sobrante S.A.
Agrícola San Antonio Limitada

$\begin{array}{lcc}\text { Río Ligua } & 37 & 4 \\ \text { Río Ligua } & 27 & 2 \\ \text { Río Ligua } & 55 & 4 \\ \text { Río Ligua } & 13 & 1 \\ \text { Río Ligua } & 39,6 & 4 \\ \text { Río Ligua } & 55 & 4 \\ \text { Río Ligua } & 9 & 1 \\ \text { Río Petorca } & 2 & 1 \\ \text { Río Petorca } & 47,2 & 18 \\ \text { Río Ligua } & 9,31 & 5 \\ \text { Río Ligua } & 11 & 1 \\ \text { Río Petorca } & 2 & 1 \\ \text { Estero Catapilco } & 23,67 & 3 \\ \text { Río Ligua } & 26,1 & 13 \\ \text { Río Ligua } & 9,5 & 5 \\ \text { Río Petorca } & 13,5 & 3 \\ \text { Río Ligua } & 2,75 & 1 \\ \text { Río Petorca } & 105,3 & 23 \\ \text { Río Petorca } & 14 & 3 \\ \text { MILIAR RUIZ-TAGLE } & \\ \quad \text { Fuente } & \text { Caudal } & \text { N }^{\circ} \\ \text { (cuenca) } & \text { L/s } & \text { Derechos } \\ \text { Sin registros } & - & - \\ \text { Costeras L-Ac. } & 22 & 4 \\ \text { Río Ligua } & 20 & 2 \\ \text { Río Ligua } & 215,6 & 24 \\ \text { Río Ligua } & 206,08 & 23 \\ \text { RAILIAR PIWONKA } & \end{array}$

\section{Nombre de Solicitante}

Sociedad Agrícola Huingal

Juan Ruiz-Tagle

Sergio Ruiz-Tagle Húmeres

Agrícola Los Ángeles de Cabildo Limitada

Sociedad Agrícola Los Ángeles de Cabildo Ltda.

ASOCIADO A GRUPO FAMILIAR PIWONKA

\section{Nombre de Solicitante}

Agrícola Pullacón

Sociedad Agrícola Pullacón Ltda.

Alberto Piwonka Zañartu

$\begin{array}{lc}\begin{array}{c}\text { Fuente } \\ \text { (Cuenca) }\end{array} & \begin{array}{c}\text { Caudal } \\ \text { L/s }\end{array} \\ \text { Río Ligua } & 236 \\ \text { Río Petorca } & 182 \\ \text { Río Ligua } & 55,5 \\ \text { Río Petorca } & 87 \\ \text { Río Ligua } & 37 \\ \text { Río Petorca } & 25\end{array}$

$\mathbf{N}^{\circ}$
Derechos
31
11
4
2
2
1

El padre de Alberto Piwonka fue, además, consultor de varias de las empresas que se adjudicaron fondos del Estado por medio de la ley 18.450 , conocida como Ley de Fomento a la Inversión Privada en obras menores de riego y drenaje de la CNR, implementada en $1985 .{ }^{14}$

14. En el Informe Anual sobre Derechos Humanos en Chile se detallan las sanciones administrativas por usurpación ilegal de aguas realizadas por la DGA a las Agrícolas Pilillén, pertenecientes a la familia Cerda (Resolución 1997, 14 de julio del 2011). A causa de extracción de aguas desde el estero Los Ángeles por parte de Agrícola El Cóndor perteneciente al exministro Eduardo Pérez Yoma (Resolución 1529, 16 de mayo del 2011). Ver informe de derechos humanos del Centro de la Universidad Diego Portales (Ver en referencias UDP 2013, 263-264). Cabe señalar que en 1994, 1996 y el 2010 el exministro Edmundo Pérez Yoma recibió fondos de la Comisión Nacional de Riego por una cantidad de $\$ 156.592 .216$ millones de pesos bajo el nombre de Sociedad Agrícola Los Graneros Limitada. Estadística Ley 18.450, al 15 de mayo del 2017. Disponible en http://www.cnr.gob.cl/Home/ SiteAssets/Paginas/Estadist icasConcursos/Estad\%c3\%adst ica\%2OLey $\% 2018450 \% 20$ al\%2015 \%20de\%20Mayo\%20de\%202017.zi $\mathrm{p}$ 
Figura 5

Montos asignados a grupos familiares denunciados por MODATIMA a través de concursos de la Ley 18.450 de la Comisión Nacional de Riego entre 1981 y 2017 (en pesos chilenos).

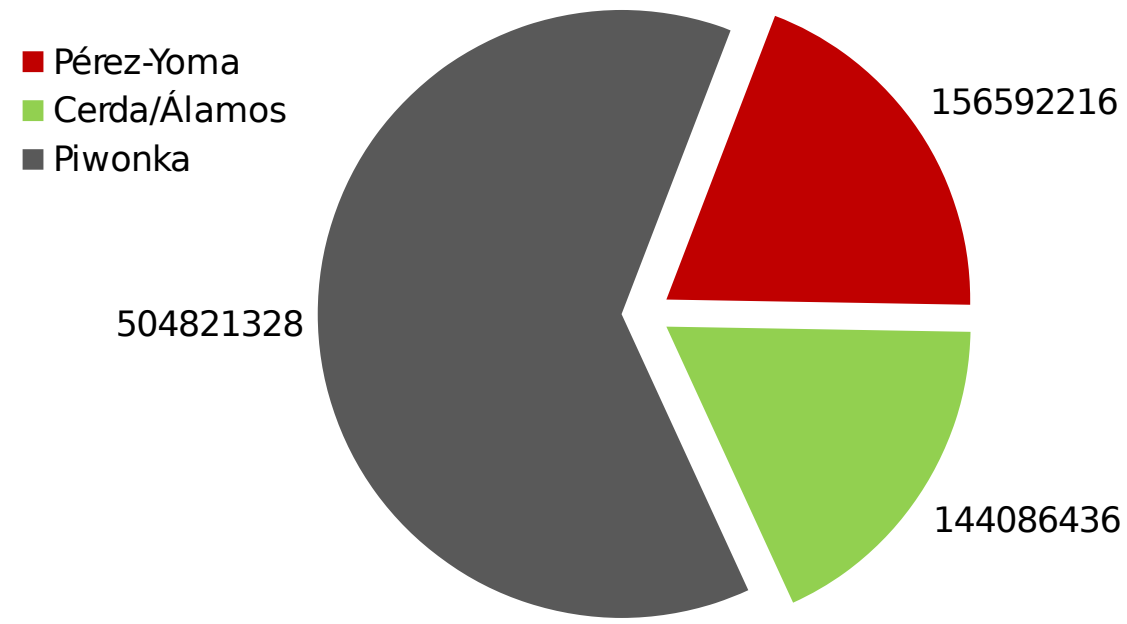

Fuente: Elaboración propia a partir de las estadísticas de la Ley 18.450 al 15 de Mayo del 2017 (CNR 2017)

Tabla 3

Montos asignados a beneficiarios asociados a grupos familiares denunciados por MODATIMA a través de concursos de la Ley 18.450 de la Comisión Nacional de Riego en el período 1981 y 2017 (en pesos chilenos).

\section{ASOCIADO A GRUPO FAMILIAR PÉREZ-YOMA/JUNEMANN}

Nombre de Beneficiario

Sociedad Agrícola Los Graneros Limitada

$\begin{array}{cc}\text { Total monto } & \text { Años en que fueron } \\ \text { asignado en el } \\ \text { período }\end{array} \quad \begin{gathered}\text { asignados montos } \\ \end{gathered}$

$\$ 156.592 .216$

\begin{tabular}{|c|c|c|}
\hline \multicolumn{3}{|c|}{ ASOCIADO A GRUPO FAMILIAR CERDAIÁLAMOS } \\
\hline Nombre de Beneficiario & $\begin{array}{l}\text { Total monto } \\
\text { asignado en el } \\
\text { período }\end{array}$ & $\begin{array}{l}\text { Años en que fueron } \\
\text { asignados montos }\end{array}$ \\
\hline Eduardo Cerda Lecaros & $\$ 8.905 .885$ & 1997 \\
\hline Fernando Antonio Álamos Cerda & $\$ 20.361 .305$ & $1987-1988,1994,1998$ \\
\hline $\begin{array}{l}\text { Francisco Ignacio Servando Álamos } \\
\text { Jordán }\end{array}$ & $\$ 13.926 .885$ & 1995 \\
\hline Francisco Javier Álamos Jordán & $\$ 26.185 .159$ & 1999 \\
\hline Jorge Joaquín Álamos Jordán & $\$ 27.703 .581$ & 1998 \\
\hline Agrícola Viento Norte Limitada & $\$ 21.363 .470$ & 2015 \\
\hline
\end{tabular}




\begin{tabular}{lcc}
\multicolumn{1}{c}{ ASOCIADO A GRUPO FAMILIAR PIWONKA } \\
Notal monto \\
Nombre de Beneficiario & $\begin{array}{c}\text { asignado en el } \\
\text { período }\end{array}$ & $\begin{array}{c}\text { Años en que fueron } \\
\text { asignados montos }\end{array}$ \\
Agrícola Pullacón Limitada & $\$ 408.946 .445$ & $1987,1994-1997,2005,2008$ \\
Sociedad Agrícola Pullacon Ltda. & $\$ 95.874 .883$ & $1986-1990$ \\
\hline
\end{tabular}

Fuente: Elaboración propia a partir de las estadísticas de la Ley 18.450 al 15 de Mayo del 2017 (CNR 2017)

El complejo y difuso puzle de los derechos de agua se configura en una parte fundamental de la crisis; se trata de un mecanismo que perpetúa la incertidumbre e invisibiliza dónde y quiénes tienen el agua. Los errores en la inscripción de derechos, así como en los datos, las figuras de titulares bajo sus nombres particulares y uso de sociedades anónimas y otras, se suman a la inscripción a nombres de familiares que no dejan vislumbrar la real magnitud del problema, ni sus principales actores. ${ }^{15} \mathrm{~A}$ su vez, la confusión manipulada para ver los procesos del sobreotorgamiento como naturales y asociados a la escasez y la sequía, revelará una doble realidad. Los mismos titulares de derechos de aguas subterráneos eran a su vez titulares de aguas provisionales en plena crisis del agua. Varios de ellos, a su vez, fueron denunciados por usurpación:

A contar de ahí y de los cambios climáticos que se vinieron y que se percibieron a través de heladas potentísimas en esta provincia que yo diría que el año 2007 se quemó por las heladas el $60 \%$ de la base productiva de la zona, nosotros comenzamos a darnos cuenta y a ver quiénes son los que tenían agua; y ya nos dimos cuenta rápidamente...que había gente que indudablemente tenía derechos de agua provisionales. Derechos de agua provisionales significa que tú los inscribes provisionalmente, o sea por un tiempo determinado, que se pueden quitar en cualquier momento en la medida de que el derecho provisional de entrega ... no afecte a terceros. Ahora, el caudal en los ríos en el año 2007 no existía; creo que el año 2006 fue la última vez que hubo algún tipo de caudal $y$, por lo tanto, nosotros nos preguntábamos: "Bueno, ¿por qué se entregan derechos provisionales si no hay agua?"
15. Al analizar las bases de datos de la DGA se presentan ciertas complicaciones, como por ejemplo que los caudales promedio anuales no están en formato numérico al exportar los datos desde la página. Se requiere, entonces, su transformación a números para ser sumados. Junto con ello, los registros de nombres de solicitantes tienen algunas diferencias menores al referirse al mismo nombre natural o jurídico - abreviaciones, puntos, faltas de ortografía, entre otras - que dificulta la agregación de datos de los solicitantes, además de casillas vacías para ciertos criterios, lo que deja cierta información como incalculable. 
Y de ahí ya empezamos el tema de la lucha por el agua, año 2008, primeros días del año 2008, concentración grande de agricultores en Cabildo, donde viene la ministra. Nosotros por primera vez denunciamos el tema del agua y en esa oportunidad con toda la estructura de la agricultura del país denunciamos a Edmundo Pérez Yoma como un usurpador de aguas... Había hecho un dren en el Estero Los Ángeles y que estaba paralizando toda el agua que escurría por las napas subterráneas. Eso por supuesto que nos costaron las penas del infierno; se colocó una demanda en contra del dirigente que dijo eso, que fue el que tenía que hablar, que en ese entonces éramos la Coordinadora de Regantes del Río Ligua-Petorca (Extracto de entrevista a pequeño agricultor de la Ligua, febrero del 2015).

\section{Palabras de cierre}

Los conflictos por el agua en Petorca son resultado de una histórica política de despojo que se aceleró con la implementación del modelo agroexportador iniciado en dictadura y consolidado en democracia. Chile, en este sentido, exportó su modelo de aguas como exitoso; no obstante, el caso de Petorca y de otras comunidades muestra la otra cara de un modelo que ha generado desigualdades socioecológicas y sufrimiento ambiental. En particular, porque ha modificado no solo la geografía y el paisaje, sino las relaciones sociales y culturales, obligando a cambios productivos que han eliminado las economías tradicionales y las han redirigido a una política centrada en la exportación de la palta. Por lo tanto, únicamente se reforzó una estructura social, política y económica existente con anterioridad a la reforma agraria: la comunidad de desiguales entre patrones y peones que experimentó un nuevo y acelerado impulso debido a una política de concentración de la tierra y del agua, legitimada por la arquitectura legal impuesta por la dictadura y consolidada por los gobiernos de centro-izquierda que gobernaron en Chile desde el retorno a la democracia en 1990.

La política económica agroexportadora impulsada en territorios semiáridos como Petorca ha utilizado el discurso de la escasez, la sequía y el cambio climático para invisibilizar el sobreotorgamiento de las aguas, en particular de 
las subterráneas, lo cual ha mostrado las falencias de la entidad a cargo de la administración del agua en manos de la Dirección General de Aguas. Aunque actualmente la DGA ha sido la principal impulsora de recortes de derechos a titulares denunciados por la usurpación a través de eliminar los derechos provisionales de aguas y ha provocado una reinterpretación jurídica a la perpetuidad como principio jurídico en la propiedad de las aguas, la DGA no ha podido cumplir con su función de fiscalizar y catastrar los derechos. De esta manera, se han revelado las dimensiones políticas que rodean los conflictos por el agua y las dificultades técnicas para enfrentar la fuerza de los extractivismos, en particular del agronegocio en la zona central chilena.

A su vez, los conflictos por el agua en Petorca generados por la sobreexplotación y el sobreotorgamiento de derechos de aguas superficiales en la década de los años 90 y, luego, de las aguas subterráneas, en el 2000, han involucrado a empresarios que han ocupado importantes cargos políticos a nivel local y senatorial. De esta manera, la fluidez y transparencia del agua son acumuladas y opacadas por una política que no considera la pequeña y mediana agricultura, y ha contrariado todas las restricciones y protecciones vigentes.

Esta política demuestra la necesidad de hacer dialogar las dimensiones cualitativas y cuantitativas en los conflictos por el agua, y analizar cómo la incertidumbre de los datos o la falta de ellos configuran en sí misma una política del agua que se sustenta y refuerza a través de los discursos sobre la sequía y la escasez para justificar la distribución de más recursos a los antiguos y nuevos agricultores asociados a la agroexportación. La política, asimismo, ha significado la desaparición, la marginación y el empobrecimiento progresivo de los pequeños agricultores, quienes debieron arrendar y vender las tierras con sus derechos asignados.

El modelo chileno privatista del agua nos ha mostrado la necesidad de estudiar las dimensiones políticas del agua desde una eco-geo-política de dicho líquido desde los territorios, tomando los aportes de las propias organizaciones que han levantado un movimiento de defensa de recuperación y defensa del agua, al mismo tiempo que han denunciado los abusos de la legislación y las paradojas de un discurso político progresista y neoliberal que, en Chile, solo ha afianzado un modelo mercantil en torno a los bienes naturales.

Hoy la defensa del agua es realizada por comunidades y organizaciones como MODATIMA, a falta de las competencias legales de la DGA, las cuales terminan delegando la tarea de abastecimiento y distribución del agua potable en las Asociaciones de Agua Potable Rural (APR). Por el contrario, el propio Estado ha incentivado dicho modelo desigual debido al incentivo económico para la construcción de infraestructura, dirigido hacia los grandes y nuevos agricultores, mediante la CNR. Paralelamente, se intenta moderar el conflicto, distribuyendo una limitada cantidad de recursos por el INDAP, corroborando el destino agroexportador que tanto el Estado como los privados tienen asignado para la provincia de Petorca. 


\section{Bibliografía}

Acosta Espinoza, Alberto. 2009. La maldición de la abundancia. Quito, Ecuador: Abya yala.

Auyero Javier y Débora Swiston. 2008. Inflamable: Estudio del sufrimiento ambiental. Buenos Aires, Argentina: Paidós.

Ávila García, Patricia. 2016. "Hacia una ecología política del agua en Latinoamérica". Revista de Estudios sociales [online]. 2016, n. ${ }^{\circ}$ 55, pp. 18-31. ISSN 0123-885X. Acceso 20 de agosto del 2017. http://dx.doi.org/10.7440/res55.2016.01

Auyero Javier y Débora Swiston. 2008. Inflamable: Estudio del sufrimiento ambiental. Buenos Aires, Argentina: Paidós.

Bauer, Carl J. 2003. "Vendiendo agua, vendiendo reformas. Lecciones de la experiencia chilena". Revista Ambiente y Desarrollo (3 y 4): 6-9.

Bakker, Karen. 2007. "The 'Commons' versus the 'Commodity': Alterglobalization, Anti-privatization and the Human Right to Water in the Global South". Antipode 39 (3): 430-455.

Bengoa Cabello, José. 2015. Historia rural del Chile Central. Tomo I. la construcción del Valle Central. Santiago, Chile: LOM ediciones.

Bolados García, Paola. 2016. "Conflictos socio-ambientales/territoriales y el surgimiento de identidades post neoliberales (Valparaíso-Chile)". Izquierdas 31: 102-129. Acceso el 5 de enero del 2017. http://www.scielo.cl/pdf/izquierdas/n31/0718-5049-izquierdas-3100102.pdf

Budds, Jessica. 2004. "Power, nature and neoliberalism: the political ecology of water in Chile". Singapore Journal of Tropical Geography, (25)3: 32242. doi:10.1111/j.0129-7619.2004.00189.x

Budds, Jessica. 2012. "La demanda, evaluación y asignación del agua en el contexto de escasez: un análisis del ciclo hidrosocial del valle del río La Ligua, Chile". Revista de Geografía Norte Grande (52): 167-184. https://dx.doi.org/10.4067/S0718-34022012000200010 
Budds, Jessica. 2004. "Power, nature and neoliberalism: the political ecology of water in Chile". Singapore Journal of Tropical Geography, (25) 3: 32242. doi:10.1111/j.0129-7619.2004.00189.x

Bustos Gallardo, Beatriz; Manuel Prieto Montt y John Barton. 2015. Ecología política: naturaleza, propiedad, conocimiento y poder. Santiago, Chile: Editorial Universitaria.

Calderón Seguel, Matías y Karen Fahrenkrog Borghero. 2012. Memorias de la reforma agraria: la lucha por la tierra en el Valle de Longotoma. Santiago, Chile: LOM.

Castillo Gallardo, Mayarí. 2016. "Desigualdades socioecológicas y sufrimiento ambiental en el conflicto "Polimetales" en Arica". Convergencia, 23(72): 89-114. Acceso el 17 de agosto de 2017. http://www.scielo.org.mx/scielo.php? script=sci_arttext\&pid=S140514352016000300089\&lng=es\&tlng=es

Castro, José Esteban. 2016. Agua y democracia en América Latina. Campina Grande. Paraíba. Brasil: Editora de la Universidad Estatal de Paraiba y Red WATERLAT-GOBACIT. Catastro Frutícola. 2014. Principales Resultados. Región de Valparaíso / Julio 2014. ODEPA-CIREN. Acceso el 10 de mayo del 2017. http://www.odepa.gob.cl/wpcontent/uploads/2012/09/CF-V-Region-Valparaiso-2014.pdf

Centro de Derechos Humanos Universidad Diego Portales. 2013. Informe El Derecho al Agua como un Derecho Humano: El Caso de la provincia de Petorca, Chile, Universidad Diego Portales. Acceso 20 agosto del 2017. http://www.derechoshumanos.udp.cl/derechoshumanos/images/Informe Anual/2013/Cap\%207\%20Derecho\%20al\%20agua\%20como\%20ddhh \%20caso\%20provincia\%20de\%20petrorca.pdf

Chile Sustentable. 2012. Usurpación de agua en los ríos La Ligua y Petorca genera riesgo sanitario y crisis de producción campesina. En Conflictos por el Agua en Chile: Urge cambios legales y constitucionales en las políticas de agua, 27-31, Santiago: Chile Sustentable.

Comisión de Sesión del Senado de la República, sobre recursos hídricos, desertificación y sequia del 14 de marzo del 2017. Acceso el 2 de junio 
del 2017. http://www.senado.cl/appsenado/index.php?

mo=comisiones\&ac=sesiones_celebradas\&idcomision $=1009 \&$ tipo $=3 \& a$

no=2017\&comi_nombre=Especial\&idsesion $=11456 \&$ fecha $=14 \% 2 F 03 \%$

2F2017\&inicio=09\%3A30\&termino=12\%3A35\&lugar $=$ Sala\&listado $=2$

Comisión Nacional de Riego. 2017. Estadística Ley 18.450. Acceso el 2 de junio del 2017.

http://www.cnr.gob.cl/Home/Paginas/EstadisticasConcursos.aspx

De Souza Santos, Bounaventura. 2012. De las dualidades a las ecologías. Editora Red Boliviana de Mujeres Transformando la Economía REMTE, Serie: Cuaderno de Trabajo n. ${ }^{\circ}$ 18. Acceso el 5 de abril del 2017. http://www.boaventuradesousasantos.pt/media/cuaderno\%2018.pdf

Dirección General de Aguas. 2004a. Actualización de la evaluación de los recursos hídricos subterráneos acuífero cuenca del río La Ligua, V Región. Santiago de Chile: DGA, Informe Técnico n. ${ }^{\circ} 166$.

Dirección General de Aguas. 2004b. Área de Restricción para un sector del acuífero del valle del río La Ligua. Santiago de Chile: DGA, Informe Técnico $\mathrm{N}^{\circ} 54$.

Escobar, Arturo. 2011. Ecología Política de la Globalidad y la Diferencia En La Naturaleza Colonizada. Héctor Alimonda (coord.), 61-92. Argentina: Clacso.

Garrido Rojas, José; Cristian Guerrero Yoacham y María Soledad Valdés. 1988. Historia de la Reforma Agraria en Chile. Santiago, Chile: Editorial Universitaria.

Grinberg, Miguel. 2012. Ecofalacias. El poder trasnacional y la expropiación del discurso verde. Rosario, Argentina: Fundación Ross.

Gudynas Silinskas, Eduardo. 2009. Ciudadanía ambiental y metaciudadanías ecológicas. Revisión y alternativas en América Latina. En Urgencia y utopía frente a la crisis de civilización. Javier Reyes Ruíz y Elba Castro Rosales (comp.), 58-101. México: Universidad de Guadalajara. http://www.gudynas.com/publicaciones/capituloslibros.htm 
Gudynas Silinskas, Eduardo. 2015. Extractivismos. ecología, economía y política de un modo de entender la naturaleza. Lima, Perú: RedgeCLAES-PTDG-Cooperacción.

Gudynas Silinskas, Eduardo. 2009. Ciudadanía ambiental y metaciudadanías ecológicas. Revisión y alternativas en América Latina. En Urgencia y utopía frente a la crisis de civilización. Javier Reyes Ruíz y Elba Castro Rosales (comp.), 58-101. México: Universidad de Guadalajara. http://www.gudynas.com/publicaciones/capituloslibros.htm Harvey, David. 2005. The New Imperialism. Oxford: University Press.

Instituto de Derechos Humanos. 2014. Informe Misión de Observación Provincia de Petorca. Instituto de Derechos Humanos, Santiago.

Lander, Edgardo. 2000 (editor). Ciencias sociales: saberes coloniales y eurocéntricos En La colonialidad del saber: eurocentrismo y ciencias sociales perspectivas latinoamericanas. Buenos Aires, Argentina: CLACSO.

Martínez Alier, Joan. 2004. El ecologismo de los pobres. Conflictos ambientales y lenguajes de valoración, Barcelona: Icaria/FLACSO.

Merlinsky, María Gabriela. 2013, Política, derechos y justicia ambiental. El conflicto del Riachuelo, Argentina: Fondo de Cultura Económica.

Ministerio de Obras Públicas. 2016. Atlas del Agua. Acceso 20 agosto del 2017. http://www.dga.cl/atlasdelagua/Paginas/default.aspx

Mundaca Cabrera, Rodrigo. 2014. La Privatización de las Aguas en Chile. Causas y resistencias, Chile, Santiago, Chile: América en Movimiento.

Murray, Warwick. 1997. "Competitive global fruit export markets: marketing intermediaries and impacts on small-scale growers in Chile". Bulletin of Latin American Research (16,1): 43-55.

Organización de las Naciones Unidas. 2002. General Comment n. ${ }^{\circ}$ 15. "The Right to Water." Arts. 11 and 12 of the International Covenant on Economic, Social and Cultural Rights. Doc. E/C.12/2002/11, 2002.

Orlove, Ben y Steven Caton. 2010. "Water Sustentability: Anthropological Approaches and Prospects". Annual Review Anthropology 39: 401-415. https://doi.org/10.1146/annurev.anthro.012809.105045 
Porto-Gonçalves, Carlos Walter. 2006. «El agua no se niega a nadie » Polis [En línea] 14: 24. Acceso el 25 octubre del 2017. http://polis.revues.org/5127

Porto-Gonçalves Carlos y Enrique Leff. 2015. "Political Ecology in Latin America: the Social Re-Appropriation of Nature, the Reinvention of Territories and the Construction of an Environmental Rationality". Desenvolvimento e Meio Ambiente 35: 65-88. Acceso el 20 de mayo de 2017.

https://www.researchgate.net/profile/Enrique_Leff/publication/30037317

3_Political_Ecology_in_Latin_America_the_Social_Reappropriation_of_ Nature_the_Reinvention_of_Territories_and_the_Construction_of_an_E nvironmental_Rationality/links/5717a9d708ae986b8b79e082/Political-

Ecology-in-Latin-America-the-Social-Re-Appropriation-of-Nature-the-

Reinvention-of-Territories-and-the-Construction-of-an-Environmental-

Rationality.pdf

Prieto Montt, Manuel. 2015. La Ecología (a) política del modelo de aguas chileno. En Ecología política en Chile: naturaleza, propiedad, conocimiento y poder. Bustos Gallardo, Beatriz; Manuel Prieto Montt y John Baron (editores),143-166. Santiago: Editorial Universitaria.

Porto-Gonçalves, Carlos Walter. 2006. «El agua no se niega a nadie », Polis [En línea] 14: 24. Publicado el 08 agosto 2012, consultado el 25 octubre 2017. URL : http://polis.revues.org/5127

Porto- Gonçalves Carlos y Enrique Leff. 2015. "Political Ecology in Latin America: the Social Re-Appropriation of Nature, the Reinvention of Territories and the Construction of an Environmental Rationality". Desenvolvimento e Meio Ambiente 35: 65-88. Acceso el 20 de mayo de 2017.

https://www.researchgate.net/profile/Enrique_Leff/publication/30037317 3_Political_Ecology_in_Latin_America_the_Social_Reappropriation_of_ Nature_the_Reinvention_of_Territories_and_the_Construction_of_an_E nvironmental_Rationality/links/5717a9d708ae986b8b79e082/PoliticalEcology-in-Latin-America-the-Social-Re-Appropriation-of-Nature-the- 
Reinvention-of-Territories-and-the-Construction-of-an-Environmental-

Rationality.pdf

Strang, Verónica. 2004. The meaning of water. Oxford: Berg.

Svampa, Maristella. 2011. Modelos de desarrollo, cuestión ambiental y giro eco-territorial. En La naturaleza Colonizada. Héctor Alimonda (coord.). Buenos aires, Argentina: Ediciones CICCUS-CLACSO.

Svampa, Maristella y Enrique Viale. 2014. Maldesarrollo. La Argentina del extractivismo y el despojo, Argentina: Kats editores. 